\title{
Critical Reflections on the Entrepreneurship Programme Designed to Develop Effectual Entrepreneurs
}

\author{
Teboho Pitso (Dr.) \\ Centre for Innovation and Entrepreneurship, Vaal University of Technology \\ Email: biki@vut.ac.za/bikipitso02@gmail.com \\ Malefane Johannes Lebusa (Dr.) \\ Centre for Innovation and Entrepreneurship, Vaal University of Technology \\ Email:johannes@@vut.ac.za/johannes.lebusa@gmail.com
}

Doi:10.5901/mjss.2014.v5n25p53

\begin{abstract}
This article reports on a study that was largely a qualitative, critical examination of the Tsohang Entrepreneurship Programme which was designed to develop effectual entrepreneurs. The programme was primarily examined in terms of its theory of change, which evaluates effectuation, as well as evaluating its effect on the trainees' mind-set, as assessed through business decision processes and improved business practices. Effectuation advances a business decision process that attempts to guide business actions and activities toward choosing particular effects on the grounds of the available means, using the principles of affordable loss, the surprise factor and network building to fabricate and reshape markets. The critical reflection theory was predominantly used for scrutiny and critique of the programme's theory of change as well as certain other aspects of the programme. This was achieved through firstly, broadly identifying and examining the deep-seated assumptions embedded in the programme's conception and applications. Secondly, the study concentrated on tracing the origins of these assumptions. Thirdly, it focussed on evaluating their relevance in our context and within the Small to Medium businesses framework and finally, on suggesting improvements to the programme. The critical reflection theory was additionally utilised to discover the extent to which programme's trainees developed alternative decision processes as a result of their exposure to the programme and how that, in turn, improved their business practices. Through collection of data and analysis of interviews as well as observation, the data were organised in the form of vignettes or critical incidents permitting these researchers to understand some of the effects of the programme on beneficiaries' decision processes and learn of improvements on their business practices.
\end{abstract}

Keywords: entrepreneurship, effectuation, Critical Reflection, decision processes, Critical Incident Technique

\section{Introduction}

Given that our democratic project commits to the fostering of Small to Medium businesses as a means of making citizens more economically active, we designed an Entrepreneurship Programme in order to meaningfully contribute to this project. Our purpose in this programme was to develop entrepreneurs that make use of effectual logic to fabricate and reshape markets. A local mining company generously financed this programme, which in 2014, is in its third year. Effectual entrepreneurship is a relatively new and dynamic heuristic problem-solving approach to fabricating and reshaping markets on grounds of well-developed decision-making processes. These processes allow for choices regarding the effects on the basis of available means and within the principles of affordable loss, the surprise factor and networks building. The approach draws on the 2001 work of Saras Sarasvathy that advances an alternative logic to the traditional logic of causation, which seeks to eliminate uncertainty and risk so as to leverage prediction and control in discovering markets (Sarasvathy 2001). The effectual logic of action embraces uncertainty and allows people to set in motion decision processes that depend on available resources, in what Sarasvathy (2001) calls "The Bird in Hand Principle"; on that basis set a course of action to aggressively take over market share in terms of building strong networks and relationships with initial customers and increasingly expanding the customer base. Furthermore, promising initial customers are viewed as potential investors in the business and relationships of trust are forged so that losses are distributed, as the said initial customers invest in the business and the business is allowed to be shaped by these customers as well as other internal or external factors, so that the surprise element is embraced. These issues are further expounded in the next section as they form part of the framing theory for the programme. A detailed elucidation of the 
Entrepreneurship Programme then follows, concentrating on: the context of implementation, its purpose, the target, its theory of change and delivery method. In the section addressing research methodology, we describe the critical reflection theory, drawing from its wide literature canvas and refocusing it as an evaluation tool. The qualitative nature of the study is also briefly described, as are the methods used in the study. We then share the results of the study and suggest a future direction of research for this area.

\section{Framing Theory}

By virtue of focusing on decision-making processes as the key element in making a distinction between effectual entrepreneurs and other entrepreneurs, SarasSarasvathy linked her approach to entrepreneurship to that of Cognitive Science. In her 2008 book entitled Effectuation: Elements of Entrepreneurial Expertise, SarasSarasvathy discusses her $\mathrm{PhD}$ work which focused on understanding the way in which expert entrepreneurs process information, reason, make decisions and perform specific actions to achieve high levels of performance that fabricate and reshape markets. She arrived at the conclusion that effectual entrepreneurs, rather than discovering and exploiting pre-existent markets and opportunities, create these opportunities from their mundane realities and value systems. They do by focusing on their intellectual, human and social capital to make, rather than seeking to find markets. With regard to intellectual capital, particular attention is paid to decision processes and consequential sets of actions taken. In an earlier study, in which Sarasvathy (2001) reviewed the literature on decision-making processes, she realized that most of the literature advanced a decision-making process based on causation. In other words, the focus was on:

1. The setting of a well-structured and specific goal to be achieved so that the starting point is a clear goal.

2. A set of alternative means or causes which is made available in order to achieve a goal

3. Strategies which are crafted to deal with constraints on possible means mainly from the environment

4. Criteria for selecting between means

It is this causation structure in the decision-making processes that Sarasvathy (2001) problematized, critiqued and attempted to improve, mainly for its tendency to promote predictive control (market research and definitive business plan) and search for high returns. In effectuation, which Sarasvathy $(2001,2008)$ advocates, decision processes pay attention to:

1. An available set of means as a starting point

2. Choices which are made on particular effects based on available means

3. Constraints on and opportunities for possible effects imposed mostly by limited available means and, the environment and its contingencies which ought to be leveraged.

4. Criteria for selecting between effects on the strength and limits of available means

The causation and effectual structures of decision-making processes, as juxtaposed and contrasted here, reveal a fundamental difference in cognitive schemas and meaning perspectives. The focus of this study falls on effectual decision-making processes and their meaning for those who are not expert entrepreneurs. It specifically concerns the way in which they can be cushioned under certain tutelage, given their generally compromised reflexive capacity which combines high intellectual and practical capabilities that expert entrepreneurs typically possess. Most of the people tutored in the programme lack MBA level training, have fewer resources than those which expert entrepreneurs command in big businesses, lack sophisticated networks and often plan or attempt to operate in markets targeted by leading brands. Our experience and research indicate that the cognitive schemas and meaning perspectives of the study's target, are decision-making processes that are mostly survivalist and focused on subsistence (Lebusa 2013, Pitso 2013 and SAMSA/VUT 2013). We sought to challenge these decision processes through our Entrepreneurship Programme tutelage and to advance effectual decision-making processes that focus on available means, the surprise factor and relationship building, as the base upon which to create and reshape markets.

Mezirow (1990) describes cognitive or meaning schemes as a set of habitual expectations of cause and effect as in if I sell this number of items then I will be able to pay rent, buy stock and food for my family. When this set of schemes influences decision processes in informal business, then certain actions and activities often become routinized, resulting in a vicious cycle of hand-to-mouth which tends to continue unabated. The cause-effect structure of decision processes is linked to the meaning perspective, which Mezirow (1990), describes as a set of assumptions with which new information gets assimilated on the basis of past experience. Cognitive schemes and meaning perspectives define our horizon of expectation, and thus affect decision processes in very significant ways (Mezirow 1990).

It is these core concepts of cognitive schemes, based on cause-effect and meaning perspectives that interpret new in terms of past experience, that we sought to confront and, where possible, defeat in our programme tutelage. The intended purpose was that trainees could begin to newly define the problems they encounter at a personal and business 
level as well as learn to accommodate new in order to expand their horizons of expectation and gain new interpretations of experience. The programme, through tutelage attempted to ensure that trainees could learn to reassess the way they see the problems and reevaluate their own orientation towards them, with a view to unearthing their deeply-held notions of problem-solving and assumptions. This was in order to bracket their prior judgements and entrenched biases to be able to hold these in abeyance, in preparation for an alternative structure of decision-making process based on effectuation.

\section{The Entrepreneurship Programme}

\subsection{Context and Purpose of Implementation}

The Tsohang Entrepreneurship Programme is designed to serve the Vaal area, which straddles two local municipalities located in two provinces of South Africa: Gauteng Province and Free State Province. The economic activity of the Emfuleni Local Municipality in Gauteng and Metsimaholo Local Municipality in the Free State remains integrated postapartheid. A 2013 study conducted by ourselves on the economic conditions of the Vaal and its impact on the well-being of its inhabitants shows, inter alia, that more than $60 \%$ of its people are economically inactive, $10 \%$ rely on social grants, $80 \%$ of its household income comes from the formal sector and its informal business sector is increasing at a slower than national average rate (SAMSA/VUT 2013). This indicates a low level of entrepreneurial activity in the area and high levels of poverty, unemployment and inequality (PUI). For instance, the Vaal Gini Coefficient, which is a measure of inequality and a summary static of income inequality that ranges from 0 as perfect equality and 1 as perfect inequality, where one household earns all the income and the rest of the households earn nothing, is estimated at 0,64 . This is reflected in income patterns where $80 \%$ of less affluent households earn $40 \%$ of the total income of the Vaal but $20 \%$ of the more affluent households earn $60 \%$ of its total income.

It is important to note that the Vaal combined Gross Geographic Product (GGP) is 7,8\% in relation to the total Gauteng GGP, with the Emfuleni GGP estimated at 5,5\%. The Vaal combined GGP shows a 3\% contribution to the national economy. Emfuleni houses $8,5 \%$ of the Gauteng population and yet contributes only $5,5 \%$ to Gauteng's economy; a clear indication that many people who are able-bodied and of sound mind are economically inactive. Tsohang, which has a sense of awakening into a new reality, was designed in light of these economic conditions. Its purpose is to provide beneficiaries with the means of critical understanding and the means to create new possibilities through challenging their entrenched cognitive schemes and meaning perspectives as key factors in decision-making processes as well as inculcating reflective action based on effectual logic.

\subsection{Target}

Tsohang focuses on existing small businesses with a view to moving them towards medium levels. The programme pays particular attention to those business owners that were disadvantaged by apartheid and attempts to up-skill them to cope and succeed in the free market zone. We also target start-ups: those individuals who develop some raw but promising ideas that may be converted into new ventures. While participants are currently drawn from within the institution and from local communities of the Vaal, there are ambitions to upscale the programme to other sections of the country at some point.

\subsection{Theory of Change}

The Tsohang theory of change has already been described in detail under "Framing Theory" and only salient points are dealt with here. Effectual entrepreneurs take three categories of means as their starting point. In the first instance, they focus internally and evaluate their traits and abilities as key determinants of deciding which markets to create or which existing ones to disrupt. The abilities that are frequently evaluated are those of analysis, synthesis and practical application:

Analytical abilities assist with critical understanding of challenges related to launching, running or expanding a business based on accuracy over available means and assessing the merit of promising ideas. Abilities of synthesis assist with making connections between ideas that would otherwise not receive the necessary attention that limits the occurrence of unforeseen circumstances These two abilities frequently play a role during the phase of generation of ideas. The third ability, application, typically involves trying out promising ideas at a practical level, using the principle of affordable loss and fabrication of markets. 
In the second instance, effectual entrepreneurs closely examine the knowledge and skills they have developed over time, to determine whether they are sufficient to create a particular market or whether there is a need to involve others who have the requisite knowledge and skills; or whether they themselves need to go for training and further development.

In the third instance, they focus on their existing social networks as potential customers and possible investors. This means that effectual entrepreneurs make use of partnerships and cooperative strategies to establish markets. They always start small and build on lessons gained along the way to expand the business. The underlying motive is that of contributing to the well-being of customers, rather than chasing profit margins. These are the types of entrepreneurs we seek to develop in our programme.

\subsection{Method of Delivery}

The programme focuses on start-ups and existing businesses, regardless of the level of education reached by owners. Our programme is designed in such a way as to prepare and practically expose trainees to situations of uncertainty where levels of risks and criticisms are high. As seed funders, we do this within the affordable loss principle and make use of small projects where trainees receive a certain amount as a loan to fabricate and reshape markets, the purpose of which is to facilitate use of alternative decision processes in real situations. The concern is not focused on immediate success, but emphasis is, rather, placed on testing out tentative plans based on lessons learned in the training. Failure is embraced and carefully examined during classes, allowing for collective learning to take place.

Training classes are held at the university, and target community members and university students. However, the student component is limited to $15 \%$. Actual contact sessions are held on Saturdays and average six hours in length per Saturday. The reason for this is that during the week trainees are given opportunities to try out the ideas, knowledge and skills gained, about which they then report back on Saturdays. The maximum number of trainees at any one time is 150. When a new cohort of trainees is taken up, they start off by doing basic computer literacy, which includes possibilities of creating new ecommerce markets. The training also includes basic financial management and development, human resources development, including Labour Relations, strategy development, value chain development, effectual entrepreneurship, mentoring, small seed-funded projects and visits to business expos.

\section{The Research Methodology and Methods}

This study is based on qualitative critical reflection theory and its variant, critical incident technique. It makes use of a critical reflection theory as a research evaluation tool in attempting to critically examine the assumptions of the Entrepreneurship Programme and reworking them to improve practice. It also makes use of a critical incident technique as a data collection mechanism to discover whether beneficiaries of the programme use alternative decision processes predicated on effectuation in their businesses and whether these have improved business practices.

Interest in critical reflection as an evaluation tool has increased in research into professional practices over the last few decades (Brookfield 1995; Gould 2004; Fook \& Askeland 2007; Fook \& Gardner 2007; Johns 2002). The literature on critical reflection tends to foreground its meaning, evaluation strategies and processes as well as the effect on practice and falls into three distinct categories, often defined in terms of purpose. Critical reflection may be primarily educational (Brookfield 1995), may frequently be located within literature on research methodology or is able to serve as a theoretical framework for making sense of the nature of social life. For the purpose of this study, literature that links critical reflection and research methodology becomes relevant, especially as it applies to the scrutiny and development of programmes and practices. However, a brief review of models and tools of a critical reflection theory is vital to demonstrate variation in using such a theory in research. Models and tools on critical reflection have been developed over time to guide research. Ghaye and Lillyman (1997) describe five different types of critical reflection models as: structured, hierarchical, iterative, synthetic and holistic, which differ in terms of their levels of prescriptiveness, flexibility and the typologies of reflection on which each is based. Johns (2002) indicates that structured models use staged sets of questions to frame and guide reflection since hierarchical models focus on guiding students through succeeding levels of reflective practices. Fook and Gardner (2007) indicate that iterative and holistic models tend to be more cyclical and place their focus on learning processes.

Tools and techniques for critical reflection have also been developed and disseminated in the literature and tend to be used in oral or written form as well as interactively or in self-reflection (Osmond \& Darlington 2005). They include critical incident techniques (Fook, White \& Gardner 2000; Hughes 2007), journalling (Bolton 2001), on-line discussions (Whipp 2003), case studies, reflective or critical conversations (Brookfield 1995; Ghaye \& Lillyman 2000c), powerful 
narratives (Lehmann 2003c), poems (Bolton 2001), ethnographic data analysis, natural case records and reports, which are vital to probe deep-seated assumptions (White \& Stancombe 2003). Nevertheless, for the purpose of this study, the definition of critical reflection is closely examined. The definition advanced by Stein (2000), as an additional way of refocusing critical reflection as an evaluation tool, is employed and links critical reflection with research methodology. According to him, (Stein 2000, 1), critical reflection refers to the process by which people identify the assumptions that govern their actions, locate the historical and cultural origins of these assumptions, question their meaning and develop alternative ways of acting. Based on this definition of critical reflection, we were able to glean an evaluation research process which assisted us to interrogate the Entrepreneurship Programme more objectively. The first step in critical reflection, based on Stein's definition, is to identify assumptions that are being made when certain actions or a set of activities are performed. Secondly, and based on step one, efforts to examine assumptions depend upon tracing their origins.

The third step relates to reviewing these assumptions in terms of specific criteria: determining the worth and merit of each assumption in line with the historical context and personal circumstances of those involved in a programme or project. Measuring worth is often context-specific and leverages a lot of local knowledge at a particular point in time. It tends thus to cater for contextual peculiarities and perturbations, unlike merit, which has a wider scope, tending to be context-independent and mostly free of time and space constraints. Models, tools and techniques used in critical reflection tend to exhibit the characteristics of worth or merit in varying degrees of sophistication. Our study takes place at a particular time and space and thus inclines toward calibrating worth through "thick" descriptions. The last step of critical reflection involves reworking our decision-making processes in order to improve the programme or project practices as well as embedding reflective action at the heart of what we do.

The researchers employed the critical incident technique for investigating whether the Entrepreneurship Programme succeeded in developing alternative logics of decision-making for those who attended the programme. It was also used to indicate whether their business practices improved as a result of attending the programme. The said technique is a well proven qualitative research approach that provides practical step-by-step procedures for collecting and analysing information about human activities and their significance to those involved (Flanagan 1954, Hughes 2007). It involves the study of carefully selected critical incidents or significant instances of a specific activity as experienced or observed by the research participants. Detailed analysis of these incidents provides researchers with opportunities to identify similarities, differences and patterns and to establish insights into how and why people engage in those activities. The critical incident technique approach was selected for this study because it tends to support practical outcomes and comprises five steps. The first step entails defining the activity to be studied and establishes its aim. Such an activity frequently represents a major turning point or crisis and includes real life incidents that are less dramatic, but which still represent aspects of human experience that are significant to specific people (Hughes 2007). The second step involves setting up plans and specifications: a detailed plan of how data will be collected is developed which includes the identification of critical incidents and recording of critical behaviours (Hughes 2007).

In developing these plans, it is important to consider the following factors to ensure consistency and objectivity of the collected data:

1. Situation: the researcher specifies the location, conditions, research participants and the activity under investigation.

2. Relevance: the researcher specifies the types of critical incidents and the nature of critical behaviours relevant to the study and worthy of being noted and recorded.

3. Extent: here criteria are set for collecting critical incidents based on their significance in terms of the extent to which their positive or negative effect has bearing on the general aim.

4. Observers: the researcher ensures that all data collectors have a good understanding of the activity being studied and receive thorough instructions and training in the data collection process.

In step three, attention is paid to the actual collection of data which means identifying and recording a critical incident or incidents that relate to the activity under investigation. The critical incident technique's preferred methods of data collection are individual interviews and direct observations because they have a sense of immediacy (Hughes 2007: 5). Interview questions, under this technique, focus on a critical incident or incidents the interviewee might have recently taken part in or observed first-hand. The interviews mostly pay attention to incidents that had positive or negative results for the activity being investigated. This technique seeks contextualized data which is significant to the activity under investigation, with a focus on time of the incident, a full description of it, explanations why it is significant in relation to the activity under investigation, what was effective or ineffective in the described incident, why it was effective or ineffective and description of an outcome or result. It is important to note that in the critical incident technique, it is the complexity of the activity and variety as well as quality of the critical incident or incidents that determine sample size rather than the 
number of participants. In this technique, the data collection and analysis occur concurrently and questions continue to be asked until there is redundancy, that is, a stage where no new critical behaviour can be recorded.

Step four of the said technique involves data analysis and is conducted at the same with step three: it focuses on an inductive data analysis process, the aim of which is to establish classification of critical incidents and identification of critical behaviours. These classifications and identification of critical incidents and behaviours, respectively, are then organized into a series of well-defined but mutually exclusive categories and sub-categories in terms of decreasing generalizability or increasing specificity. Categories are expected to have a frame of reference which delineates aims of the activity and the intended application of data as ways of developing broad categories and sub-categories. Formulation of categories allows the researcher to sift through the critical incidents, identify critical behaviours, and then place them in categories or sub-categories (Hughes 2007, 7). Once these categories and sub-categories are completed, interpretation and reporting in line with the intended application of data follow as step five. The focus of interpretation is on a set of critical behaviours that define the activity; here, it concerns whether alternative decision processes and basic principles of effectuation have been applied and have made a difference in business practices.

\section{Results}

\subsection{On Assumptions of the Programme}

We can place the assumptions we make in the programme in theoretical, conceptual, implementation, outcomes and contextual categories. Regarding theoretical assumptions, we believe that decision processes that are based on effectuation are more likely to successfully launch a new venture, allowing existing businesses to fabricate new markets and disrupt existing ones. We further assume that a theory developed from the practices of highly experienced and expert entrepreneurs who command huge resources in large companies is able to be sufficiently modified to serve the creation of new ventures or the expansion of small to medium businesses by ordinary people. We also presuppose that ordinary people who have the intent to open or expand a business are capable of exhibiting relatively high levels of performance under conditions of uncertainty, high risk and complexity. if...?

Concerning the issue of conceptual assumptions, we have a sense that training effectual entrepreneurs in the $21^{\text {st }}$ century ought to start with basic computer literacy. We regard basic financial accounting, Labour Relations, Human Resources Development (note: not management), value-chain development, strategy development, effectual entrepreneurship concepts and tools, small seed-funded projects and visits to expos as having the capacity to sufficiently prepare our target to fabricate and reshape markets. It is also our belief that the said group is capable of working independently most of the time and that its members are able to deal with very fluid projects as well as failure. Our assumptions regarding programme implementation are the following:

- Two months of basic computer training focused on basic computer skills, ecommerce opportunities and marketing strategies are likely to contribute in enhancing new venture creations or the expansion of existing small businesses.

- That a further four months of training on basic business skills, exposure to market creation in line with effectual logic of action through small seed-funded projects, presentations offered in class for peer scrutiny and actual visits to expos are likely to develop effectual entrepreneurs who have a different orientation to problemsolving.

- That the use of experts in basic computer and business skills will result in better learning than training provided by novice facilitators.

- That the university ambience is more likely to motivate our target to attend regularly; some may even pursue formal learning as a result of this exposure.

With regard to assumptions concerning outcomes, in our opinion a six-month intensive training course and exposure to real market situations will result in individuals becoming oriented towards effectual decision processes and new venture creations as well as being able to operate and expand businesses more successfully. We further believe that such training is more likely to develop aggressively competing yet strategically collaborative entrepreneurs who are creative, innovative and strong as regards practical application. In our opinion, the more businesses are operated by entrepreneurs developed in this manner, the greater the likelihood of increasing numbers of people becoming economically active.

Concerning the issue of contextual assumptions, the Vaal is a highly industrialized area at the hub of Gauteng, with more than three towns and six townships as well as mushrooming informal settlements which provide ample opportunities 
for small to medium businesses to thrive. We have further assumed that with the decline of manufacturing in the Vaal, which was the dominant economic sector, alternative downstream economic activity may be harnessed through small to medium businesses. We also assume that the Vaal, with its historic significance: the 1900s Vereeniging Peace Treaty, the 1960 Sharpeville massacre, and the 1990s Boipatong massacre, as well as its waterways (Vaal River, Vaal Dam, Bedworth Lake, and Sharpeville Lake) holds significant tourism opportunities for small to medium businesses.

\subsection{Tracing the Origins of these Assumptions}

Our theoretical assumptions originate in the PhD work of Sarasvathy as already stated earlier and hinge on the idea of using effectual logic and downplaying, without entirely discarding, causal logic in business decision-making processes. This theory of effectuation has its origins in the US, which means it was developed under economic conditions that are materially different from our South African context and thus problematizes importation. The theory was also gleaned from experienced experts that command huge resources in big business and thus required modification to cater for use by novices and less resourced individuals with less business, market and network exposure and without MBA level training.

The conceptualization of the programme may be traced from our experience as academic developers with PhDlevel expertise in innovation and entrepreneurship, local and international benchmarking of similar programmes and $21^{\text {st }}$ century trends, specifically mass computerization and a knowledge-based economy, as well as its capacity to operate on a global scale in real time. One of the researchers studied creativity and innovation at PhD level and spent time in Sweden and the US to deepen understanding at a practice level while the other holds a PhD in Entrepreneurship and spent time in Denmark to better understand how effectuation is implemented in practice.

We have also, over many years, been developing training programmes and have taken them through pilots and iterative processes, in this way establishing a reasonable understanding of how training programmes are better able to be conceptualized for maximum impact. Our international benchmark has also proved relevant in programme conceptualization.

Similarly, this implementation model draws from our collective wisdom and a deep and personal understanding of our context and the historical trajectory of our country. We knew the importance of defeating the debilitating and pernicious inferiority built over years by deliberate acts of policy and education and how this had tended to encourage subsistence entrepreneurship. Therefore, the focus of implementation was to ensure that trainees, irrespective of their level of education, have access to the means of critical understanding of the wider context of a neo-liberal economic setup and how it may be mapped out at the local level where they have already begun or plan to set up a business. We also felt it necessary that trainees have access to the means of heuristic problem-solving in the form of effectuation and TRIZ as means of exploring new possibilities. TRIZ is a heuristic problem-solving technique that originates in the Engineering discipline and focuses on searching for higher designs of situations, technologies and systems (Pitso 2013). It is based on challenging the maximum constraint (the final form of situation or product) and seeking its ideal state. We believe market situations are always ripe for disruption as new ones are fabricated, because often their state of equilibrium involves (presumed) satisfied, overshot and non-consuming customers. Overshot customers are those who receive a product or service in a very inconvenient way because of location and over-pricing, while non-consuming customers are those who do not have current interest in or find it difficult to access a product or service and have accepted such an economic condition. The maximum constraint of an economic situation, in this case, involves these unmet needs. Effectual entrepreneurs often firstly target locations where levels of satisfaction are presumably high, as this provides opportunities to fabricate and reshape these markets either through low-end disruption by offering lowercost business models (relatively low prices and convenient access) or, frequently, by means of leveraging collective bargaining (from entrepreneurship forums for bulk buying and negotiating better prices).

Secondly, they compete against non-consumption, which could be the result of inconvenient locations due to low socio-economic conditions, poor access, poorly-developed infrastructure, psychological inertia evolving out of inaccessibility or distance between business location and access to products or service.

Our outcomes assumptions developed out of our deep sense that our theoretical and implementation models provide sufficient infrastructural capacity for successful launches of new ventures and expansion of small businesses toward medium levels.

Contextual assumptions draw from our deep understanding of the area which we attained from our direct experience and the research we conducted in 2013, which also augmented earlier studies carried out by the Vaal Research Group in 2003 and 2004. Our research in the area also includes identification of economic sectors that indicate potential for increased economic activity over the next three to four decades, and consequently provide opportunities for our trainees to fabricate and reshape rather than discover these markets. We make the point that any economic sector in 
the area can be turned into a successful market space for our trainees as long as they dominantly make use of effectual logic of action that illuminates the fabrication and reshaping of markets.

\subsection{Determining the Worth of these Assumptions}

This section examines the appropriateness, relevance, value-addedness and effectiveness of the assumptions we make in this programme.

- Effectuation has been studied and tested over the last decade, mainly within the framework of high performing expert entrepreneurs with access to huge resources and operating within the context of big business. We adapted effectuation to operate within small to medium level businesses where owners often command scant resources. We kept the effectual logic intact as well as effectuation principles of affordable loss, the surprise factor and network building. We introduced tutelage which we define as "helpful influence" because our belief is that effectual entrepreneurship, as with all other forms of entrepreneurship, is able to be learned.

We also believe that entrepreneurship is a "contact sport": one just has to do it and practise constantly until one gets it right; hence our small projects. We also added some seed-funding to support really promising ideas and small projects. This framing of the programme was iteratively tested and was refined from 2009 until 2010, when a national bank financially supported these initiatives. We have reasonable grounds to suggest that our theory of change has been sufficiently adapted and tested for effectiveness in building the confidence and self-belief of trainees so that they can use effectual decision processes to initiate and successfully complete entrepreneurial tasks. Of the 2009-2010 cohorts of trainees, almost twenty percent of them re-joined formal study at our university and most continue to run small businesses. One of the trainees converted a bicycle into a motorbike that reaches the speed of $80 \mathrm{~km} / \mathrm{h}$ and currently continues to sell them. Other trainees co-operated in starting a shoe manufacturing company that also provides training for shoe-making and repairing. The 2012-2014 cohorts of trainees have also successfully launched or expanded their businesses. It is this evidence of some success that enables us to suggest that our modified theory of change has proved to be effective and, with further refinement, will increase our rate of success in launching new ventures and expanding existing businesses by those who experience our programme tutelage. We thus consider effectuation as our theory of change relevant to our context of training, thereby adding value to our programme and its beneficiaries.

- Our implementation model provides training on computer literacy mainly because we acknowledge the centrality of technology in enhancing business bottom-lines in the $21^{\text {st }}$ century in terms of access to information as well as the marketing opportunities technology makes available. We also inculcate elementary business skills, based on the principle that business ideas are evolving all the time and that the competitive edge of a business is based on the use of the latest concepts and tools of business. The rapid growth of knowledge and information in the $21^{\text {st }}$ century and the undergirding of our economic activity that they provide (Castells 2001; Peters 2003) strengthen our resolve that business skills shared with our programme beneficiaries should be fluid rather than constant.

- We thus believe that our model of implementation is relevant to the prevailing global context of doing business. The fact that a number of our beneficiaries became sufficiently motivated to study at university suggest that our decision to conduct training at the university has a positive effect and added value to our programme. The fact that seed-funded beneficiaries have been able to go on to run successful small businesses demonstrates the workability of the model. We have reason to suggest, though, that the model is still able to be improved.

- Developing effectual entrepreneurs who make a difference in terms of contributing towards making more people economically active in the area has resulted in some success stories but not at the rate we would have preferred. Linked to the contextual assumptions we make, outcomes that we seek to achieve in this programme are appropriate and relevant but difficult to produce in ways that could positively impact the economic activity of the area, increase the area's contribution to the national economy and reduce its Gini Coefficient. We remain convinced that with greater cooperation from government, through the implementation of the National Development Plan of which we form part, the rate of success in launching new ventures and expanding existing small businesses could increase. We employ the Triple Helix Model which involves us (a university), the private sector and government to promote entrepreneurship through guided innovation. The role of government has generally been weak and has thus affected our rate of success, compromising our value addedness and effectiveness in combating the triple challenges of poverty, unemployment and inequality 
- Our conceptual model, that includes effectuation as our theory of change and tutelage of basic computer and business skills as well as the university setting and six-month time frame, have met with some success. Nevertheless, in our opinion, as we have intimated, the success rate could still improve. We therefore still consider our conceptual model as appropriate and relevant, and as having modest value and effectiveness at this stage.

\subsection{Deciding on Programme Improvements}

The areas of the programme that require further refinement are the theory of change and some aspects of the implementation model. A further issue that needs serious attention is the government involvement in the programme through the Local Economic Development units, Incubation hubs and some seed-funding. The theory of change is currently too specifically focused on effectual decision processes and could benefit from TRIZ as a problem-solving mechanism, with inclination towards ideality search. This could strengthen our programme tutelage and consequently the learning that takes place. We could also increase trainees' exposure levels through more small projects and we could find other ways of enhancing their reputation capital and low resource base.

\subsection{Tracking changes and Improvements on Business Practices}

We purposively selected three trainees to follow their progress during our training, in order to determine whether they have employed some aspects of the effectual logic of action. Central to such logic is the notion of decision-making under conditions of uncertainty and taking action, even when odds are stacked against one as long as the principles of affordable loss, the surprise factor and network building form an integral part of decisions and actions. In the next section, we describe three of these trainees, focusing mainly on critical incidents they identified and assessing whether sufficient grounds exist to suggest that effectual logic was central to the actuation of the identified critical incidents. We begin with a brief background of each trainee and the promising idea each has been nurturing and we have been incubating.

\subsubsection{Vignette 1}

Trainee 1 is our university Auditing student who graduated in April 2014. He joined our 2013/2014 programme. The question is whether the critical incidents he mentioned during the interview could have been influenced by the effectual decision processes that he learned from our programme, and if so, how these led to new interpretations of an experience and improved practice. Trainee 1 identified four critical incidents of significance in his life.

He talked about his registration and completion of his three-year Diploma in Auditing, his registration and participation in the Tsohang Entrepreneurship Programme, his growing entrepreneurial self-efficacy and his tip to the Minister of Finance which was selected as the best amongst 3000 such tips and earned him a one-on-one meeting with the Minister and a meeting with the President of the country. The interview focused mainly on his participation in Tsohang. He joined the programme because he had a sense that its message that students should be creators rather than seekers of employment, resonated with his views. This happened in August 2013 and prompted him to register for the programme. On why this was significant to him, he explained that it offered a materially different approach to his studies and some of the earlier entrepreneurship programmes offered within and outside of the university. In particular, he mentioned its focus on a change in mind-set and gaining new perspectives as well as the practical application of ideas through small projects. This motivated him to visit and browse the Department of National Treasury website for possible opportunities, where he found a page that invited users to leave tips for combating economic constraints. He commented that three months in the Tsohang Programme had built enough confidence for him to try out something, as part of reshaping the space under consideration.

In November 2013, he left his tip on the website: it focused on strategies for youth development, youth entrepreneurship and employment, mentorship challenges and, support for and access to, entrepreneurship information. He is currently pursuing the access to entrepreneurship information as a market niche for himself and is being incubated in this enterprise through Tsohang. He further says that his successful tip to the Minister of Finance has opened new doors for him and built influential relationships and networks with powerful individuals that will be of importance when implementing his business idea. In May 2014, he received the Youth Award from the Sedibeng District Municipality of the Gauteng Province and attributes his growing recognition to the training he received in Tsohang: "I acknowledge the knowledge and grooming I gained and the exposure and approach to entrepreneurship I received from the department (Centre for Innovation and Entrepreneurship under which Tsohang falls)...including that entrepreneurship is the future for 
the state of our country's economy".

In his 2014 Budget Speech, Minister Gordhan had this to say about the student "... (name withheld) a student at the (name withheld) University of Technology, quite rightly advises that 'government should have clear strategies for youth development and employment for the next five to 20 years".

\subsubsection{Vignette 2}

Trainee 2 is a community member in her early forties who joined our 2013/2014 Tsohang Programme. She was already the owner of a catering company when she joined our programme. She identified three incidents that she considered as significant in her life. The first was the launch of her business about five years earlier, motivated by her desire for selfpreservation and to make a contribution to those excluded from economic participation by hiring some of them with the purpose of offering employment. She has, since learning from Tsohang, expanded her purpose of hiring people to include training, so that her employees are now seen as strategic future partners and competitors. The second incident involved joining Tsohang in August 2013, the benefits of which were to gain insights and implement certain ideas on how to expand and qualitatively improve her business practice through identifying her available resources and choosing to expand and improve her quality of business, using the principle of affordable loss. Prior to joining Tsohang, she had been thinking about expansion and quality improvement, but lacked the framework to do so which, her interview data suggest, she gained through Tsohang. One such incident, which constitutes the third incident she described, involved teaming up with another trainee from Tsohang who has produced an alcoholic beverage similar to the established brand of Amarula Cream. She added this beverage to her overall catering smorgasbord as part of providing better service to the customer and also assisting the thirty-five year-old start-up manufacturer from Tsohang, to promote her product.

\subsubsection{Vignette 3}

Trainee 3 is the thirty-five year-old start-up manufacturer described in vignette 2. She described three incidents that she viewed as significant. Firstly, her registration with Tsohang, which she described as invaluable in terms of not only assisting her to generate a manufacturing idea, but also providing her with the means through small projects, practically approached, to test out her concept of producing an alcoholic beverage by way of preparing a prototype and taking it through iterative processes of refinement, which are currently ongoing. She secondly considered her improved understanding of the processes of manufacturing and how her current six-week fermentation process could be reduced, to optimize the manufacturing process without compromising quality, as well as the creation of her bottling and label (packaging) by another company that benefited from Tsohang in the 2011/2012 intake, as significant. She finally considered her partnering with Trainee 2, as described in vignette 2, as invaluable.

When juxtaposing and contrasting these trainees, points of commonality and difference emerge.

Category 1: Profile of Trainees

- Two of the trainees are community members while one is a university student.

- The businesses of two of the trainees are start-ups whereas the business of the third trainee is already running

- Two of the trainees are youths while one is an adult

- Two trainees are female; one male.

Category 2: Identification of Critical behaviours

- Joining Tsohang Programme: all three trainees joined the programme and identify this action as critical

- Starting with available means: all three trainees used the means available to them as their starting point. Trainee 1 used computer infrastructure available at the university. Trainee 2 used her own business to promote a new product while Trainee 3 used ingredients that are reasonably easy to source, even at home.

- Unique features of each business: advisory service for youth entrepreneurship; catering with style, which now includes a locally-produced beverage and locally-produced beverage that seeks to compete with Amarula Cream.

- Relationship and network building: one trainee has linked with government to support youth entrepreneurship and empowerment whereas the other two have established relationships with each other so that one added value to an existing business and the other received support to promote a new beverage product.

Category 3: Effect on Business Practice

1. The real effect of critical behaviour on trainees' businesses is evident in the existing business where the set- 
up, decorations and menu options now include the locally-produced beverage which is generating interest as based on some observation that was made.

2. The start-ups are in their early stages with regard to making a firm determination, but prototypes are available and indicate good prospects.

Category 4: Incubation

- Each of these three businesses, along with twenty others, will continue to receive support by way of monitoring, refining, iterative testing and seed-funding for another year from Tsohang.

- Ongoing evaluation also helps to identify areas requiring support, which is then provided.

- Advisory services are also provided.

\section{Conclusion and Future Direction of Research}

We can reasonably infer the following from our reflection on our programme:

1. Our theory of change (effectuation) has generally been successfully modified to impact on the small to medium business space where there is a modicum of expertise and resources which could become even more powerful when linked with TRIZ.

2. Our conceptual and implementation models, while requiring further refinement, have proved to be moderately effective and could benefit from a refined theory of change.

3. The logic and principles of effectuation have shown promising success in fostering business practices.

4. Interviews with trainees suggest that their ways of thinking have changed as a result of attending the programme and that they could not have acted in the way that they did if they had not received such training as the programme offers. This provides some grounds for linking effectual logic and improved trainees' decision-making.

We view the following areas as ripe for further research:

- The integration of effectual logic and TRIZ to strengthen our theory of change operational within small to medium businesses

- Impact evaluation of the relationship between effectual logic and improved business practices

- Effectual entrepreneurship: conceptions, distinctions and impact in the wider entrepreneurship field is this not over done by other scholars

- Effectuation and high performance of what????

\section{References}

Bolton, G. (2001). Reflective Practice: Writing for Professional Development. London: Sage. Brookfield, S. (1995). Becoming a Critically Reflective Teacher. San Francisco: Jossey Bass.

Flanagan, J. (1954). The Critical Incident Technique. The Psychological Bulletin 5(4): 327-358.

Fook, J. \& Gardner, F. (2007). Practising Critical Reflection: A Handbook. London: Open University Press.

Fook, J. \& Askeland. (2007). Challenges of Critical Reflection: 'Nothing Ventured, Nothing Gained'. SocialWorkEducation 1: 1-14.

Fook, J., White, S. \& Gardner, F. (2006).Critical Reflection: A Review of Contemporary Literature and Understandings. In: S. White, J. Fook \& F. Gardner. Critical Reflection in Health and Social Care. Maidenhead: Open University Press. Pp. 3-20.

Ghaye, T. \& Lillyman, S. (1997). Learning Journals and Critical Incidents: Reflective Practice for Healthcare Professionals. Salisbury: Mark Allen.

Gould, N. (2004). The Learning Organisation and Reflective Practice: The Emergence of a Concept. UK: Ashgate.

Hughes, H. (2007). Critical Incident Technique. In: S. LIPU (Ed.) Exploring Methods in Information Literacy Research in Australasian Library and Information Studies. WaggaWagga, N.S.W: Charles Sturt University Press. Pp. 49-66.

Johns, C. (2002). Guided Reflection: Advancing Practice. Oxford, UK: Blackwell Science.

Lebusa, J. (2013). The Prospects of Making Small Retail Outlets Aggressively Competitive. The Southern Africa Journal of Entrepreneurship and Small Business Management 6: 75-86.

Lehmann, J. (2003c). Practice-Based Stories. Children Australia 28(1): 29-33.

Mezirow, J. (1990). How Critical Reflection Triggers Transformative Learning. In: S. Mezirow \& Associates. Fostering Critical Reflection in Adulthood. San Francisco: Jossey Bass. Pp. 1-20.

Osmond, J. \& Darlington, Y. (2005). Reflective Analysis: Techniques for Facilitating Reflection. Australian Social Work 58(1): 3-14.

Pitso, T. (2013).The Creativity Model for Fostering Greater Synergy between Engineering Classroom and Industrial Activities for Advancement of Students' Creativity and Innovation. The International Journal of Engineering Education 29(5): 1136-1143.

Samsa/VUT Research (2013).The Economic Conditions of the Vaal. Available @ www.vut.ac.za/Centre for Innovation and Entrepreneurship. Accessed on 04 March 2014. 
Sarasvathy, S. (2001). Causation and Effectuation: Toward a Theoretical Shift from Economic Inevitability to Entrepreneurial Contingency. The Academy of Management Review 26(2): 243-263.

Sarasvathy, S. (2008). Effectuation: Elements of Entrepreneurial Expertise (New Horizons in Entrepreneurship). UK: Edward Edgar Publishing.

Stein, D. (2000). Teaching Critical Reflection. Available Online @ inspirediving.com. Accessed 20/02/2014.

Whipp, J. (2003). Scaffolding Critical Reflection in Online Discussions. Journal of Teacher Education 54(4): 321-333.

White, S. \& STANCOMBE, J. (2003). Clinical Judgement in the Health and Welfare Professions: Extending the Evidence Base. Maidenhead: Open University Press. 